\title{
Atenção às populações vulneráveis: desafio para os profissionais de saúde
}

A presente edição da revista O Mundo da Saúde tem como tema central a Atenção às Populações Vulneráveis, campo que se configura em um desafio para os profissionais de saúde.

Definir vulnerabilidade não é uma tarefa simples, uma vez que está relacionada a fatores individuais, socioeconômicos, culturais, ou seja, não é um conceito absoluto, mas que nos exige um olhar aprofundado e ciente de sua complexidade. Podemos dizer que o ser humano é sempre vulnerável, uma vez que, de uma maneira mais genérica, podemos defini-la como situação de se estar sujeito a risco e, para tanto, basta estar vivo. No entanto, algumas condições nos colocam frente à concretização dessa vulnerabilidade.

Quando olhamos para o campo da saúde, podemos observar que o próprio fato de estar doente já se configura em estar vulnerável - adoecer, de alguma forma, implica perder o controle sobre seu corpo, suas funções e, em última instância, muitas vezes, sobre sua vida cotidiana. Essa situação se agrava quando nos voltamos às pessoas que, pelos mais diversos fatores, estão mais sujeitadas aos vários condicionantes da relação saúde-doença.

Pensar na atenção às necessidades particulares dessa parcela da população é um desafio para os profissionais de saúde, na busca de oferecer não apenas cuidados técnicos, mas assistência que configure em real possibilidade de promover transformações.

Para que se possa atingir tal intento, e de acordo com as atuais diretrizes para a atenção à saúde, é preciso que se respeite o princípio da integralidade, definido na política de saúde que rege o SUS. A concepção de atenção integral implica a ideia de um sistema de saúde eficiente, pautado por uma estratégia de ação centrada no usuário - define, portanto, a necessidade de integrar serviços e profissionais.

Para esses últimos, particularmente, indica a importância do trabalho em equipe e da visão interdisciplinar, de forma que se busque a superação do olhar fragmentado do especialista sobre o sujeito que se apresenta na condição de seu cliente. Não negando a necessidade da especialidade, essa deve se configurar em um instrumento para a compreensão da complexidade da relação saúde-doença e seu impacto no cotidiano dos usuários dos serviços de saúde.

É na busca de contribuir com a construção de reflexões e práticas cientificamente ancoradas, que possam subsidiar os profissionais na busca do aprimoramento de suas ações, que esta edição publica pesquisas originais, que abordam, pelas mais diversas óticas, a questão da atenção em saúde à população vulnerável, além de trazer um artigo de revisão que permite melhor compreensão deste conceito e dessa condição.

Leo Pessini*

Celina Camargo Bartalotti**

DOI: $10.15343 / 0104-7809.20143802127128$

* Pós-Doutor pela Universidade de Edinboro - Instituto de Bioética James F. Drane, Pensilvânia, EUA. Doutor em Teologia/Bioética. Pós-graduado em Clinical Pastoral Education and Bioethics at St Luke's Medical Center. Docente do Programa Stricto sensu em Bioética (Mestrado, Doutorado e Pós-Doutorado) do Centro Universitário São Camilo-SP, Brasil. E-mail: pessini@saocamilo-sp.br

** Terapeuta Ocupacional. Doutora em Educação - Psicologia da Educação pela PUC-SP. Mestre em Psicologia da Educação pela PUC-SP. Coordenadora do Curso de Terapia Ocupacional do Centro Universitário São Camilo. E-mail: celinac@saocamilo-sp.br 